LA-14163

Approved for public release;

distribution is unlimited.

\title{
Stress Measurements in Shock-Loaded PBX 9501 with Embedded Longitudinal and Lateral Piezoresistive Ytterbium Gauges
}

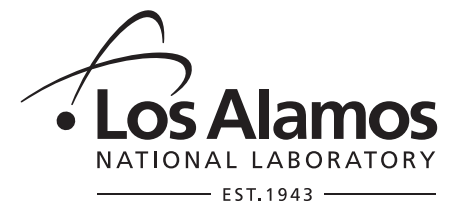

The World's Greatest Science Protecting America 
Los Alamos National Laboratory, an affirmative action/equal opportunity employer, is operated by the University of California for the United States Department of Energy under contract W-7405-ENG-36.

This report was prepared as an account of work sponsored by an agency of the United States Government. Neither the Regents of the University of California, the United States Government nor any agency thereof, nor any of their employees make any warranty, express or implied, or assume any legal liability or responsibility for the accuracy, completeness, or usefulness of any information, apparatus, product, or process disclosed, or represent that its use would not infringe privately owned rights. Reference herein to any specific commercial product, process, or service by trade name, trademark, manufacturer, or otherwise does not necessarily constitute or imply its endorsement, recommendation, or favoring by the Regents of the University of California, the United States Government, or any agency thereof. The views and opinions of authors expressed herein do not necessarily state or reflect those of the Regents of the University of California, the United States Government, or any agency thereof. Los Alamos National Laboratory strongly supports academic freedom and a researcher's right to publish; as an institution, however, the Laboratory does not endorse the viewpoint of a publication or guarantee its technical correctness. 
LA-14163

Issued: December 2004

Stress Measurements in Shock-Loaded

PBX 9501 with Embedded Longitudinal

and Lateral Piezoresistive Ytterbium Gauges

Daniel E. Hooks

Jerry J. Dick

A. Richard Martinez 


\title{
Stress Measurements in Shock-Loaded PBX 9501 with Embedded Longitudinal and Lateral Piezoresistive Ytterbium Gauges
}

\author{
Daniel E. Hooks, Jerry J. Dick, and A. Richard Martinez
}

\begin{abstract}
A series of light gas gun impact experiments were performed with piezoresistive ytterbium (Yb) gauges in longitudinal and lateral orientations embedded in the plastic bonded explosive PBX 9501. These experiments were performed to evaluate the feasibility of using this method to measure lateral stresses and shear strength dynamically in PBX 9501. Ytterbium was chosen as a gauge material based on its high piezoresistance changes at low stress levels. Experiments were performed at longitudinal impact stresses of approximately $0.6 \mathrm{GPa}$, which is above the yield point of $\mathrm{Yb}$, near the dynamic yield point of PBX 9501, at a level that is comparable with other impact data, and relevant to several multidimensional safety tests. Results show that PBX 9501 does maintain strength throughout compression. Because of poor reproducibility observed in the experiments presented, it appears unlikely that stress extraction from these gauge results would yield an estimate of shear strength at this impact stress with acceptable error.
\end{abstract}

\section{INTRODUCTION}

The multidimensional stress state of explosives undergoing shock compression is important in a variety of accident scenarios. Because of the difficulty of measuring inmaterial stresses accurately during high-rate dynamic loading, little is known about the lateral stresses imparted in materials in these situations. Although longitudinal stress information can be inferred from a variety of methods, one of the difficulties in measuring the complete stress state of materials undergoing shock compression is accessing information about the lateral stress response. One dynamic lateral stress response measurement technique involves the use of piezoresistive gauges mounted at different orientations in the shocked material. ${ }^{1}$ While manganin and carbon gauges have been used successfully for in-material stress measurements, ytterbium $(\mathrm{Yb})$ is uniquely suited for measurements with good response below about $2 \mathrm{GPa}^{2-4}$

The use of piezoresistive gauges requires that the resistance change of the gauges be calibrated to a specific sample material stress by some means. This calibration has been performed by two distinct means. One involves an attempt to understand the piezoresistance properties of the gauging material completely and the second involves a simple empirical calibration of the gauge material embedded in a material with known longitudinal response. In the first method, which in this paper we will refer to as "Gupta's method," careful dynamic and static measurement of the properties of the foils used in gauge construction 
were combined with Eshelby's inclusion approximation ${ }^{5}$ to extract stresses. ${ }^{6-13}$ At first glance this method seems robust, but gauge calibration by this method is time consuming and the analysis requires "forward-analysis" to achieve stresses from experiment.

The empirical calibration technique, which we will call "Rosenberg's method" here, offers greater simplicity in that once gauges are calibrated in a known material the calibration can be applied to measurements made in any number of unknown materials. ${ }^{14-22}$ However, additional assumptions are made, the most troubling of which are that gauge-sample interactions are assumed to be constant and that all of the resistance changes are due to sample material stresses alone. This was the technique employed in the first use of lateral gauges, and in that report it was noted that errors were very large at low stresses. ${ }^{1}$ There is severe controversy over the approximations made by both of these methods, ${ }^{23,24}$ but the empirical gauge calibration method has been used successfully in a variety of materials over the last several years. ${ }^{25-33}$ Gupta's method, as a result of its difficulty, has not been widely adopted and Gupta himself conceded that an empirical technique was most practical, though he maintains that his technique is more rigorous than Rosenberg's. ${ }^{13}$ Notable to this work, however, Gupta's forward analysis method was used for a longitudinal stress measurement in impacted Composition B-3 explosive. ${ }^{34}$ In the Sutherland report ${ }^{34}$ it was noted that this was a tedious measurement with fairly large errors.

The goal of this work was to develop a technique to measure the shear strength near the dynamic yield point, the Hugoniot elastic limit, in PBX 9501. Material properties at this low impact stress are important for model development and validation in multidimensional materials tests for a variety of hazard scenarios. The Hugoniot elastic limit of PBX 9501 is $0.14 \mathrm{GPa}$, as estimated from embedded electromagnetic gauge data for impact at 0.29 and $0.56 \mathrm{GPa}{ }^{35,36}$ Lagrangian analysis performed on this data to produce stress-strain information is available also. ${ }^{37}$ Piezoresistance gauges are used under the assumption that gauge response is perfectly plastic. The yield point of $\mathrm{Yb}$ is approximately $0.4 \mathrm{GPa}$. Experiments were performed at longitudinal impact stresses of just under 0.6 GPa, which is above the yield point of Yb, near the dynamic yield point of PBX 9501, at a level that is comparable with other impact data, and relevant to several multidimensional safety tests.

Most of the measurements made using Rosenberg's method employed commercial epoxy-encapsulated Manganin gauges, which were not ideal for these experiments because of their low piezoresistance response at the stress levels of interest. Since a commercial encapsulated $\mathrm{Yb}$ gauge package is not currently available, an experimental design similar to that used by Gupta's method was decided on. The main drawbacks of this technique are the much more difficult task of Yb gauge calibration and large errors. Given these problems and the controversial nature of these gauges, gauge reproducibility was tested at a single stress level in a few gauge inclusion geometries prior to deciding which full calibration method to use.

Gupta's method maintains that grooves machined to perfectly accommodate gauge foils better approximate an inclusion. Alternatively, there is some concern about this arrangement as it may needlessly complicate wave passage over the gauge area. Both methods, with and without machined grooves, were tested in this work. Also, because wave dispersion with depth was noted in PBX 9501 in the previous low-pressure impact experiments, ${ }^{36}$ shots were designed with $\mathrm{Yb}$ gauges placed at different depths to ensure that this dispersion did not affect resistance change measurements. 
Gauge response in polymethylmethacrylate (PMMA) was tested simultaneously to check reproducibility in the same geometries in this material and to compare relative response of the gauge in PBX 9501 and PMMA. It was hoped that if gauge response was similar in these two materials, an empirical calibration at a single stress level of the gauges in PMMA, with known deviatoric response, would allow stress extraction in PBX 9501. ${ }^{38}$ If gauge response was different, gauge calibration in PBX 9501 at varying stress levels then could be performed similarly to Rosenberg's method. If all of these failed, then a full calibration according to Gupta's method could be carried out.

In a previous report we presented results for some of these measurements, in which PMMA calibration shots were used for stress conversion in PBX 9501 shots with identical gauge geometry as just discussed. ${ }^{39}$ This type of empirical calibration resulted in widely differing estimates of shear strength, none of which were comparable with estimated values. Also, because the longitudinal and lateral gauges were placed at different depths in all of the experiments presented, it was not known whether wave dispersion with depth was influencing results.

A review of the complete data set presented below reveals uniform response for all gauge geometries in PMMA, but differing responses in PBX 9501, suggesting that there is indeed a differing response and the inclusion assumptions may not be entirely correct. The results demonstrate the difficulties of using piezoresistive gauges, and especially with regard to the assumptions involved about their inclusion and interaction with the material tested. Lateral gauges placed at slightly different depths yielded indistinguishable results. Because of poor shot-to-shot reproducibility and unexplained differences in response between shot geometries, it appears unlikely that either of the two common methods used to extract stresses from these gauges would yield an estimate of lateral stress or shear strength at this impact stress with acceptable error. Using the single-stress PMMA calibration results, a shear strength of $0.106 \mathrm{GPa}$ is estimated for PBX 9501.

\section{METHODS}

Ytterbium gauge measurements at ambient conditions were made on PMMA and PBX 9501 to evaluate the feasibility of using these gauges to estimate the complete stress state in PBX 9501. Three target designs were tested by plate impact in a gas gun.

\section{Material}

Ytterbium gauges were stamped from a $0.050 \mathrm{~mm}$ foil rolled by Santoku America, Inc. from a single ingot. The same batch of foils was used in all experiments and the gauges were stamped from the foils in single direction to ensure consistency with the rolling direction. The foils were connected to the gauge circuit using silver-bearing, lead-free, solid wire solder. UVA II grade PMMA was machined as necessary. PBX 9501 was machined as necessary from a single pressing, with nominal density $1.83 \mathrm{~g} / \mathrm{cc}$. The density of each machined piece was measured by immersion density and confirmed to be within density specifications. The target was assembled on an aluminum plate and the gauges were glued in place with Aralhex glue. 


\section{Ytterbium Gauge Design}

The nominal dimensions of the gauges and the gauge wiring are depicted in Figure 1. Measured dimensions were within $0.001 \mathrm{~mm}$ in thickness and about $0.005 \mathrm{~mm}$ in other dimensions from the nominal values. The active element of each gauge had a typical resistivity of $0.08 \Omega$, and was wired to a set of resistors to give an overall gauge package with a typical resistance of $51.1 \Omega$. This arrangement allows approximation of relative resistivity change with the measured relative voltage change. ${ }^{11}$ The Cal-Av 1520AR current supply used in these experiments delivers a pulse of about $5 \mathrm{~A}$ across the gauge element and has been modified to allow for rapid charging. ${ }^{11}$

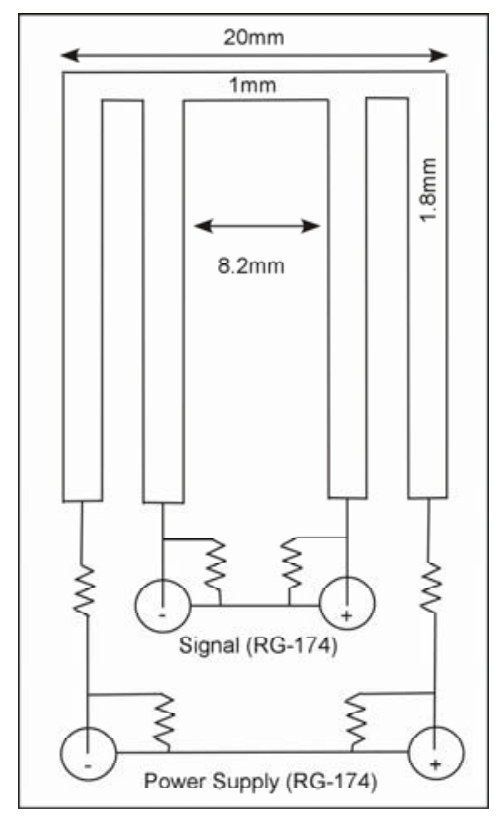

Figure 1: Gauge dimensions and wiring scheme. By increasing gauge element resistance to an overall resistance of about 50 ohms in the circuit, the resistance change is simply approximated as the voltage change.

\section{Target Design}

Three target designs are depicted in Figure 2. To measure both longitudinal and lateral stresses, Yb gauges were mounted in the target with their large-area faces both perpendicular (longitudinal) and parallel (lateral) to the direction of shock propagation. Two arrangements had the longitudinal gauges mounted $2 \mathrm{~mm}$ off center at $2 \mathrm{~mm}$ depth, and the lateral gauges mounted on center at $4 \mathrm{~mm}$ depth from the impact plane. In the first of these designs ("Target Design 1") grooves were machined to the gauge thickness to accommodate the gauges, while the second ("Target Design 2") lacked such grooves. A third design ("Target Design 3") had both gauges mounted $2 \mathrm{~mm}$ from the impact plane and $2 \mathrm{~mm}$ off center, and also lacked grooves. This third design was tested to ensure that continuing wave dispersion with increasing depth that is known to occur in PBX 9501 at this stress level did not affect the measured relative voltage change. All designs had an overall diameter of $50.8 \mathrm{~mm}$ and thickness of $12.7 \mathrm{~mm}$. 


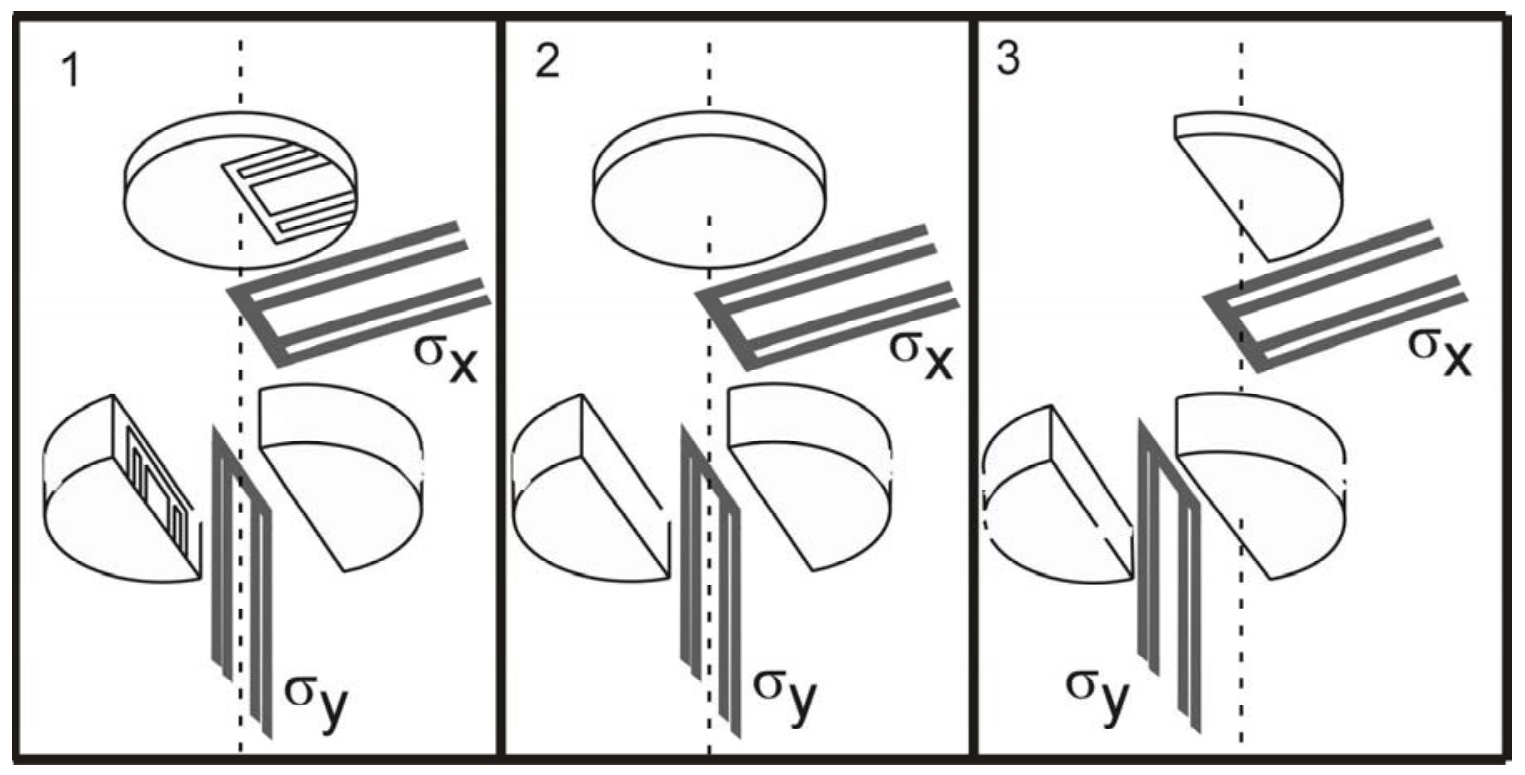

Figure 2. Schematic drawings of the three target designs used in this work. Impact is from the top. Longitudinal gauges are shown as " $\sigma_{x}$ " and lateral gauges are shown as " $\sigma_{y}$." Target Design 1 had machined grooves to accommodate the gauges, the longitudinal gauges were $2 \mathrm{~mm}$ off center at $2 \mathrm{~mm}$ depth, and the lateral gauges were on center and at $4 \mathrm{~mm}$ depth. Target Design 2 was the same as Target Design 1, except for a lack of grooves. Target Design 3 again had no grooves, but both the longitudinal and lateral gauges were $2 \mathrm{~mm}$ off center at $2 \mathrm{~mm}$ depth.

\section{Gun Experiments}

The input shock was produced by impacting a projectile launched in a single stage light gas gun onto the target. The projectile was a $1.6 \mathrm{~kg}$ aluminum/lexan solid design with an impactor mounted at the end. The impactor, $4.5 \mathrm{~mm}$ thick, was either PBX 9501 or PMMA as necessary for a symmetric impact and was backed by $5 \mathrm{~mm}$ of syntactic foam.

The diameter and depth of the targets were such that edge effects did not complicate the measurements. Projectile velocities were calculated to produce impact stresses of approximately 0.6 GPa, and projectile velocities were measured by a series of shorting pins just prior to impact. Pressurized argon was used to launch the projectiles. Data was collected on Tektronix TDS 684B digitizers. Piezoelectric transducer (PZT) pins (Dynasen, Inc), mounted $2 \mathrm{~mm}$ (PBX 9501) or $2.5 \mathrm{~mm}$ (PMMA) in front of the impact plane, were used to trigger the current pulse and digitizers. 


\section{RESULTS}

Four shots, two each in PMMA and PBX 9501, were fired with gauges at different depths with grooves machined to accommodate the gauges (Target Design 1). Resistance change waveforms are shown in Figure 3. The PBX 9501 shots exhibited slower rise times than the PMMA shots, as expected, and all waveforms showed a relatively smooth response. The lateral gauges in the PBX 9501 shots exhibited a larger response than the longitudinal gauges. Also, the lateral gauges in PBX 9501 exhibited continuously increasing responses slightly throughout compression, never reaching a steady state.

For Target Design 2, seven shots, three in PMMA and four in PBX 9501, were fired with gauges at different depths without machined grooves to accommodate the gauges. Resistance change waveforms are shown in Figures 4 (PMMA) and 5 (PBX 9501) for each of these shots. The results from the PMMA shots were nearly indistinguishable from the grooved shots, although there was some variation in steady-state resistivity change. The waveforms in PBX 9501 were not as smooth as in the previous geometry with machined grooves, with some unexplained features observed during the rise. A steady state was sometimes never achieved for either gauge. The relative gauge response in PBX 9501 generally was the opposite of the grooved shots, with the lateral gauges showing a lower response than the longitudinal gauges. The projectile velocity data was lost for one of the PMMA shots (Shot 1250), so the velocity in this case was calculated from the firing pressure.

Four shots, two each in PMMA and PBX 9501, were fired with gauges at the same depth and without machined grooves to accommodate the gauges, for Target Design 3. Resistance change waveforms are shown in Figure 6. Data from Shot 1287 was lost as a result of an error in triggering. Waveforms in this geometry were more irregular, probably because of the proximity of both gauges to a three-way glue joint and because of the increased difficulty of assembling this specific target design. Shot 1288 in PMMA was observed to have bubbles in the glue joint prior to the shot, and it resulted in a choppy waveform with larger responses and larger errors than usual. The purpose of these shots in Target Design 3 was to verify that the response of the gauges in PBX 9501 was similar to that in the shots fired in Target Design 2 to rule out wave-dispersion effects; the PMMA shots were not repeated.

A summary of all shots is given in tabular form in Table 1 . Because a steady state response was not achieved in either gauge in many of the shots, the relative resistance change given in the table is an average of the response from just after the initial rise until just before the release or end of usable data, whichever came first. Standard deviations are given for these average values, and can be quite large. Figure 7 presents plots of the average resistance change for each gauge as a function of calculated impact stress for each shot. The impact stresses given in Table 1 and Figure 7 are calculated from the measured projectile velocity and the intersection of a Hugoniot with itself for symmetric impact where particle velocity is assumed to be $1 / 2$ of the flyer velocity (PBX 9501: $\rho=1.83$, c $=2.41, \mathrm{~s}=2.39^{35}$; PMMA: $\left.\rho=1.186, \mathrm{c}=2.774, \mathrm{~s}=2.182, \mathrm{q}=-2.014^{40}\right)$. 

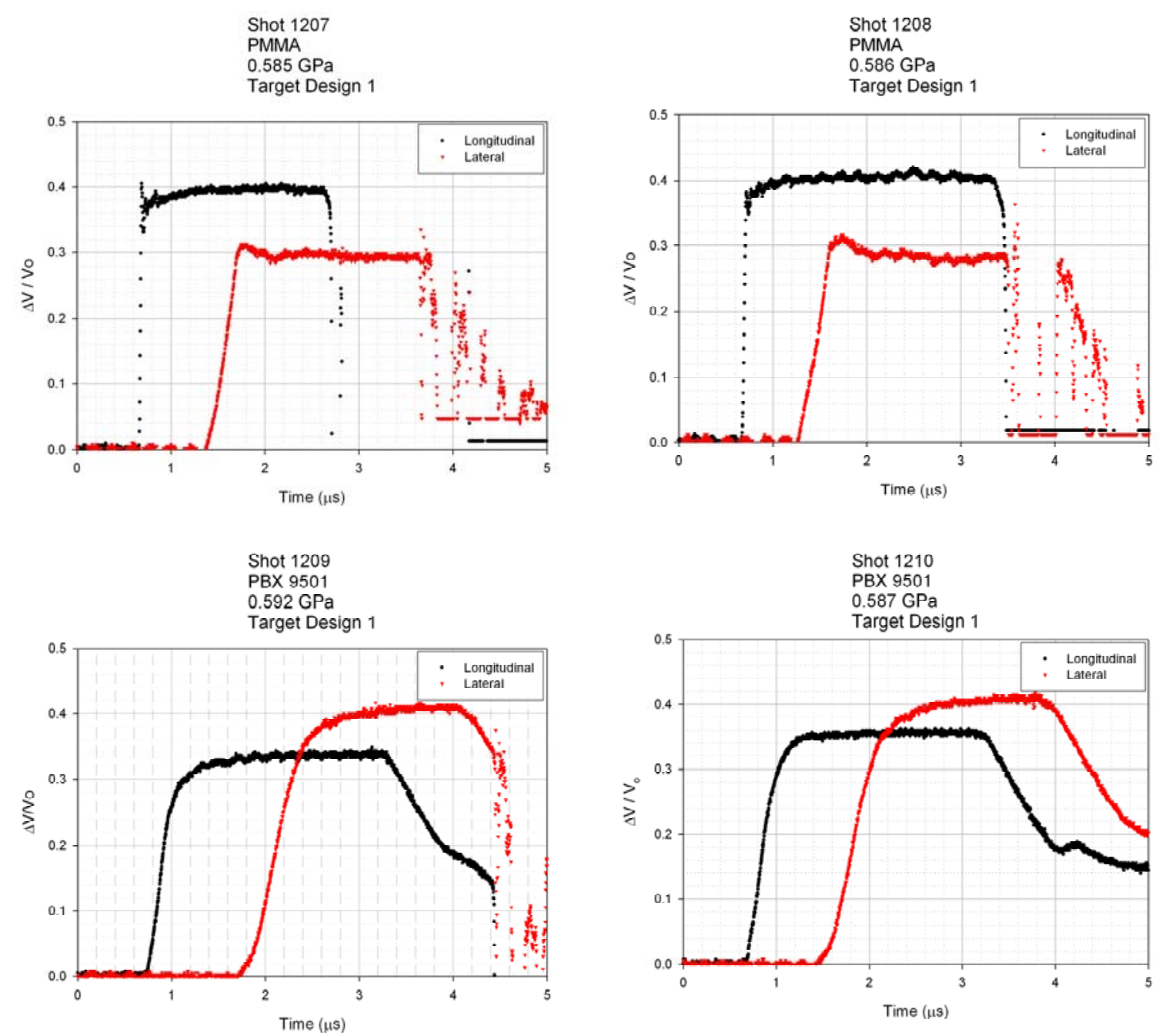

Figure 3: Target Design 1, all shots. Impact is at $0 \mu \mathrm{s}$. 

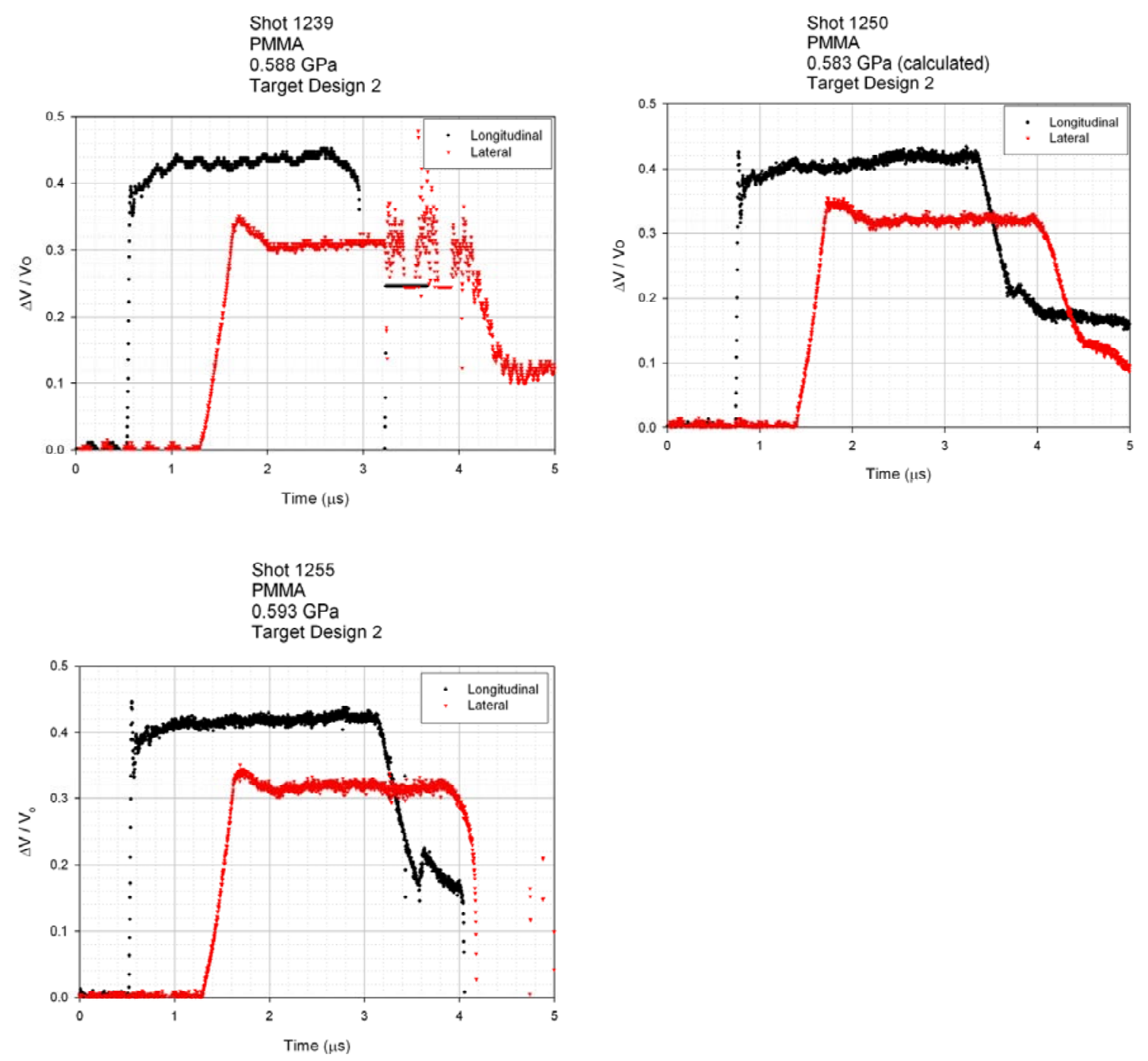

Figure 4: Target Design 2, PMMA shots. Impact is at $0 \mu \mathrm{s}$. 

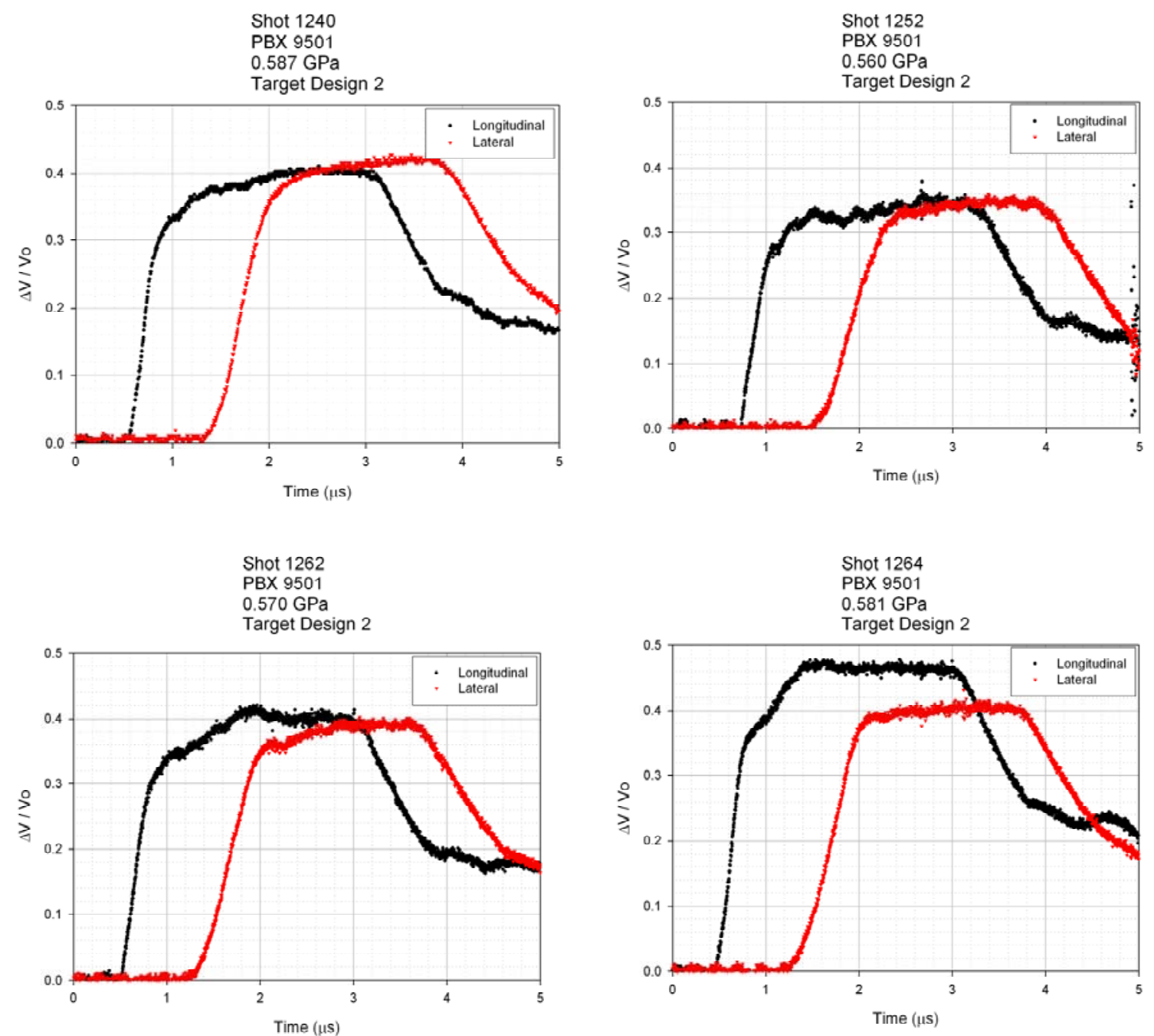

Figure 5: Target Design 2, PBX 9501 shots. Impact is at $0 \mu \mathrm{s}$. 

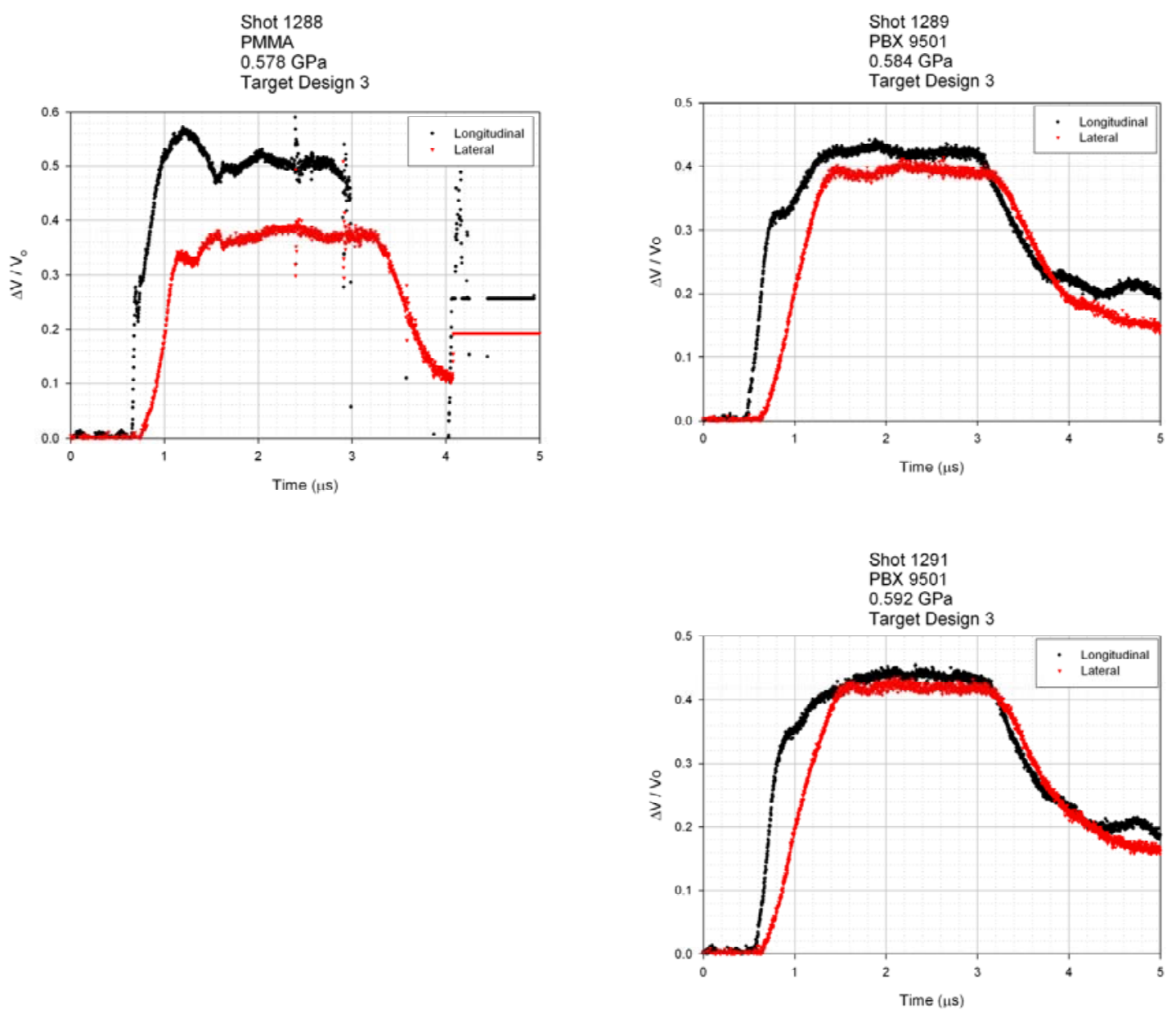

Figure 6: Target Design 3, all shots. Impact is at $0 \mu \mathrm{s}$. 
Table 1: Summary of results. Shots in PMMA are listed first, then shots in PBX 9501, starting with Shot 1209. Longitudinal gauge information is denoted by " $x$ " and lateral gauge information is denoted by " $y$." The calculated impact stress was arrived at by simple Hugoniot calculation with the measured projectile velocity. The projectile velocity in Shot 1250 is calculated from firing pressure, and Shot 1287 is not listed because the data was lost as a result of a triggering error. Standard deviations for average gauge responses are given in parentheses.

\begin{tabular}{|c|c|c|c|c|c|c|c|}
\hline Shot \# & $\begin{array}{c}\text { Target } \\
\text { Design }\end{array}$ & $\begin{array}{l}\text { Projectile } \\
\text { Velocity } \\
(\mathrm{mm} / \mu \mathrm{s})\end{array}$ & $\begin{array}{c}\text { Calculated } \\
\sigma \times(\mathrm{GPa})\end{array}$ & $\Delta$ V/Vo x & $\Delta \mathrm{V} / \mathrm{Vo} \mathrm{y}$ & $\mathrm{U}(\mathrm{x}) \mathrm{mm} / \mu \mathrm{s}$ & $\mathrm{U}(\mathrm{y}) \mathrm{mm} / \mu \mathrm{s}$ \\
\hline 1207 & 1 & 0.321 & 0.585 & $0.392(0.007)$ & $0.296(0.005)$ & 3.11 & 2.95 \\
\hline 1208 & 1 & 0.322 & 0.586 & $0.403(0.009)$ & $0.287(0.009)$ & 3.03 & 3.34 \\
\hline 1239 & 2 & 0.323 & 0.588 & $0.344(0.076)$ & $0.304(0.023)$ & 1.97 & 2.3 \\
\hline 1250 & 2 & $0.321^{*}$ & 0.583 & $0.406(0.013)$ & $0.321(0.005)$ & 2.742 & 2.903 \\
\hline 1255 & 2 & 0.325 & 0.593 & $0.411(0.031)$ & $0.318(0.007)$ & 3.97 & 3.16 \\
\hline 1288 & 3 & 0.318 & 0.578 & $0.508(0.080)$ & $0.371(0.030)$ & 3.06 & 2.73 \\
\hline 1209 & 1 & 0.241 & 0.592 & $0.330(0.003)$ & $0.402(0.038)$ & 2.73 & 2.32 \\
\hline 1210 & 1 & 0.239 & 0.587 & $0.354(0.004)$ & $0.399(0.012)$ & 2.78 & 1.617 \\
\hline 1240 & 2 & 0.239 & 0.587 & $0.386(0.019)$ & $0.411(0.009)$ & 3.62 & 2.96 \\
\hline 1252 & 2 & 0.228 & 0.56 & $0.333(0.012)$ & $0.342(0.007)$ & 2.62 & 2.44 \\
\hline 1262 & 2 & 0.232 & 0.57 & $0.383(0.029)$ & $0.380(0.014)$ & 3.81 & 2.93 \\
\hline 1264 & 2 & 0.236 & 0.581 & $0.447(0.034)$ & $0.399(0.007)$ & 4.036 & 3.01 \\
\hline 1289 & 3 & 0.237 & 0.584 & $0.406(0.033)$ & $0.393(0.006)$ & 4.028 & 2.84 \\
\hline 1291 & 3 & 0.240 & 0.592 & $0.421(0.026)$ & $0.420(0.005)$ & 3.497 & 2.942 \\
\hline
\end{tabular}
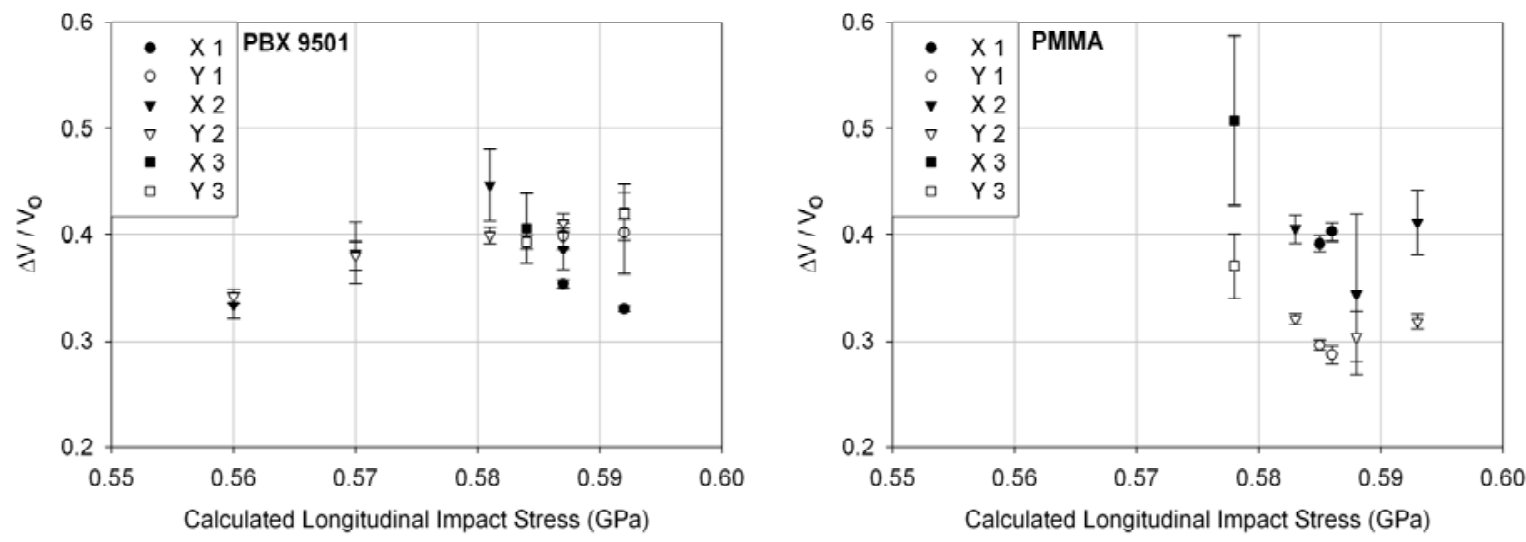

Figure 7: Gauge response summary, all shots. Longitudinal and lateral gauges are denoted by " $x$ " and " $y$," respectively. The target designs are indicated by numbers. 
A time of impact can be calculated from the projectile velocity and the trigger standoff, and with this information and the initial response time of the gauges, an apparent shock velocity in PBX 9501 can be inferred. These values are given in Table 2. Shock speeds are artificially fast for the following reason. In typical practice, shock arrival time is taken at $50 \%$ or $90 \%$ of the initial rise response in the gauge. However, because judging the length of rise is difficult in these profiles, and because rise times in the longitudinal and lateral gauges differ as a result of the differing gauge widths, arrival time was taken at just $5 \%$ above baseline in these measurements. Figure 8 presents plots of the apparent shock velocity calculated in this manner vs. calculated longitudinal impact stress for each of the gauges. This is a rather imprecise way to make this measurement, but it allows another check of gauge response. Accepted values at this stress level are about $3.2 \mathrm{~mm} / \mu \mathrm{s}$ for PBX 9501 and $2.6 \mathrm{~mm} / \mu \mathrm{s}$ for PMMA. Errors were not calculated independently for each inferred shock velocity, but are estimated to be about $\pm 0.45 \mathrm{~mm} / \mu \mathrm{s}$ for lateral gauges and $\pm 0.15 \mathrm{~mm} / \mu \mathrm{s}$ for longitudinal gauges.

Table 2: Gauge response to stress conversion. PMMA shots are listed first, then PBX 9501 shots, starting with Shot 1209. All stresses are in GPa. This longitudinal stress in the PMMA shots is assumed to be the impact stress calculated from the intersection of the Hugoniot with itself at the measured projectile velocity. The lateral stresses in the PMMA are assumed to be 0.585 times the longitudinal stress from a simplified empirical calibration. The average of the ratio of stress/gauge response in all of the PMMA shots is then applied to each of the gauge responses in the PBX 9501 shots to obtain stress. The averages of the longitudinal stress in PBX 9501 were 0.516, 0.598, and $0.577 \mathrm{GPa}$ for the grooved, ungrooved, and all shots respectively. The averages of the deviatoric stress were $0.0402,0.1331$, and $0.1061 \mathrm{GPa}$ for the grooved, ungrooved, and all shots respectively.

\begin{tabular}{llllll}
\hline \hline Shot \# & \multicolumn{1}{c}{$\sigma \mathbf{x}$} & \multicolumn{1}{c}{$\sigma \mathbf{y}$} & $\begin{array}{c}\text { Stress I } \\
\text { Response } \\
(\mathbf{x})\end{array}$ & $\begin{array}{c}\text { Stress I } \\
\text { Response } \\
(\mathbf{y})\end{array}$ & $\sigma \mathbf{x}-\sigma \mathbf{y}$ \\
\hline & & & & & \\
1207 & 0.585 & 0.342 & 1.49 & 1.15 & 0.243 \\
1208 & 0.586 & 0.343 & 1.46 & 1.2 & 0.243 \\
1239 & 0.588 & 0.344 & 1.71 & 1.13 & 0.244 \\
1250 & 0.583 & 0.341 & 1.44 & 1.06 & 0.242 \\
1255 & 0.593 & 0.347 & 1.44 & 1.09 & 0.246 \\
1288 & 0.578 & 0.338 & 1.14 & 0.91 & 0.24 \\
& & & & & \\
1209 & 0.498 & 0.4778 & 1.51 & 1.19 & 0.0202 \\
1210 & 0.5344 & 0.4743 & 1.51 & 1.19 & 0.0601 \\
1240 & 0.5833 & 0.4891 & 1.51 & 1.19 & 0.0942 \\
1252 & 0.5034 & 0.407 & 1.51 & 1.19 & 0.0964 \\
1262 & 0.5782 & 0.4524 & 1.51 & 1.19 & 0.1258 \\
1264 & 0.675 & 0.475 & 1.51 & 1.19 & 0.2 \\
1289 & 0.6129 & 0.4678 & 1.51 & 1.19 & 0.1451 \\
1291 & 0.636 & 0.4992 & 1.51 & 1.19 & 0.1368 \\
\hline \hline
\end{tabular}



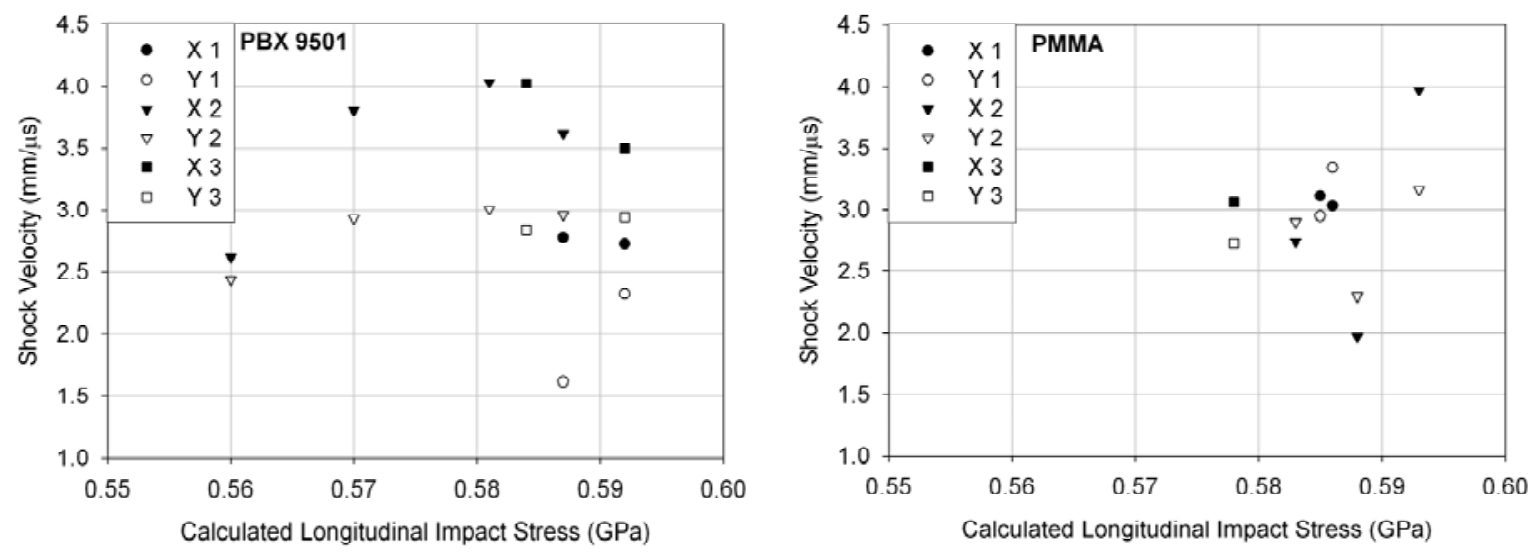

Figure 8: Inferred shock velocities from arrival times at both gauges in all shots. Longitudinal and lateral gauges are denoted by " $x$ " and " $y$," respectively. The target designs are indicated by number. Accepted values at this stress level are about 3.2 for PBX 9501 and 2.6 for PMMA. Shock velocity errors were not figured independently for each point, but are estimated to be about 0.45 for lateral gauges and 0.15 for longitudinal gauges.

\section{DISCUSSION}

Shots in PMMA, while not as numerous as those in PBX 9501, were generally consistent for both grooved and ungrooved shots. Rise times were consistent with shock velocities across the width of the gauge in both orientations, ultimate response levels were steady after the initial response, and shock velocities inferred from arrival times were reasonable. As mentioned above, Shot 1288 in PMMA was observed to have included bubbles in the glue joint prior to the shot and resulted in a choppy waveform with larger responses and larger errors than usual.

Shot results in PBX 9501 were more dependent upon the specific target design. Grooved shots (Target Design 1) resulted in apparently lower gauge response than all of the other shots, lower inferred shock velocities, and higher gauge response in the lateral gauge than in the longitudinal gauge. For these reasons, it seems reasonable to place more trust in the result of the ungrooved shots of Target Designs 2 and 3. Other than some slight differences in rise behavior, the ungrooved shots in PBX 9501 were fairly consistent. Rise times were longer than those observed in PMMA, but this was expected because of wave dispersion discussed above. For the longitudinal gauges in particular, most shots either never achieved a steady value of resistance response, or took a long time (over half of the pulse duration) to do so. The reason for this behavior is not known, but similar waveforms were observed in previous longitudinal measurements in Composition B-3. ${ }^{34}$ 
Results from Target Design 3 in PBX 9501 reveal that wave dispersion is not having a measurable effect on the resulting relative piezoresistance changes between the longitudinal and lateral gauges. In fact, because rise behavior was so irregular in all cases, it is hard to judge where the end of the actual rise is. Averaged responses were nonetheless indistinguishable from those of Target Design 2.

One significant unexpected result was that the response of the lateral gauges in PBX 9501 was more reproducible than the response of the longitudinal gauges. The lateral gauges, as a whole, showed smoother waveforms with less equilibration time and achieved an average response that was uniform from shot to shot. This result is especially apparent in plots of response and apparent shock velocity vs. stress, which are shown in Figures 7 and 8.

Because of poor shot-to-shot reproducibility and unexplained differences in response between shot geometries, it appears unlikely that either of the two common methods used to extract stresses from these gauges would yield an estimate of lateral stress or shear strength at this impact stress with acceptable error. To salvage some information from these experiments, another empirical strategy was suggested. ${ }^{38}$ Because the shear response of shock-impacted PMMA has been well-characterized, ${ }^{41}$ the longitudinal and lateral strengths can be used to calibrate gauges in each respective orientation. In this calibration, the longitudinal gauge is assumed to express the calculated longitudinal impact stress, while the lateral gauge is assumed to express a value that is 0.585 times the longitudinal stress. ${ }^{41}$ From the longitudinal and lateral stresses determined in this manner, a ratio of gauge response to stress was calculated. This was repeated for each of the shots in PMMA, and because no difference between target designs was observed, all were averaged together to give multipliers of 1.51 for the longitudinal gauge and 1.19 for the lateral gauge. For shots in PBX 9501, the multipliers just given were applied to the $\Delta \mathrm{R} / \mathrm{R}$ values achieved from each shot ( $\Delta \mathrm{R} / \mathrm{R}$ was assumed to be equivalent to $\Delta \mathrm{V} / \mathrm{V}$ because of the circuit connection). The deviatoric stress is then simply $\sigma_{\mathrm{x}}-\sigma_{\mathrm{y}}=0.040 \mathrm{GPa}$ for the grooved shots, $0.133 \mathrm{GPa}$ for the ungrooved shots, and 0.106 GPa for all shots. By using the estimated Hugoniot elastic limit $(0.140 \mathrm{GPa})$ and the ambient Poisson's ratio (0.36), a deviatoric stress of $0.061 \mathrm{GPa}$ results. Further, from a LaGrangian analysis of particle velocity data from a magnetic gauge placed at $2.3 \mathrm{~mm}$ depth, the ultimate longitudinal stress is expected to be about $0.550 \mathrm{GPa}$. The average longitudinal stress was 0.516 for the grooved shots, $0.598 \mathrm{GPa}$ for the ungrooved shots, and $0.577 \mathrm{GPa}$ for all shots. Table 2 summarizes this analysis.

\section{SUMMARY}

The use of piezoresistive gauges to measure low stresses is hindered by large errors. As these results have shown, the use of a secondary material to calibrate these types of gauges is not ideal because gauge-sample interactions vary. The best estimate of deviatoric strength of PBX 9501 at $0.6 \mathrm{GPa}$ is $0.106 \mathrm{GPa}$, which is quite different from the $0.061 \mathrm{GPa}$ estimated by other means. As a result, it must be emphasized that the main conclusion of this work is that this method was determined to be an inadequate way to measure stresses in this application; the strength estimate is not intended for use in important models. While the measured stress levels in the longitudinal and lateral directions and the resultant deviatoric stress are rather imprecise, the fact that PBX 9501 does support lateral stresses during shock for the duration of the impulse is an important conclusion. 


\section{ACKNOWLEDGEMENTS}

This work was performed under the auspices of the US Department of Energy by the University of California's Los Alamos National Laboratory, and was supported by a US Department of Energy / Department of Defense Office of Land Warfare and Munitions Memorandum of Understanding under Technical Communication Group I. Conversations with Ralph Menikoff and Mike Wong were valuable to our interpretation of results.

\section{REFERENCES}

1. P. F. Chartagnac, J. Appl. Phys. 53, 948-953 (1982).

2. M. J. Ginsberg, "Effect of Stress on the Electrical Resistance of Ytterbium and Calibration of Ytterbium Stress Transducers,” Defense Nuclear Agency report DNA001-72-C-0146 (1973).

3. D. D. Keough, "Development of a High-Sensitivity Piezoresitive Stress Transducer of the Low Kilobar Range,” Defense Nuclear Agency report DNA001-72-C-0146 (1973).

4. Y. M. Gupta and D. F. Walter, "Piezoresistance Response of Ytterbium Under Static and Dynamic Loading,” Air Force Office of Scientific Research report F49620-81-K0002 (1982).

5. $\quad$ J. D. Eshelby, Proc. R. Soc. London, Ser. A 241, 376 (1957).

6. Y. M. Gupta, J. Appl. Phys. 54, 6256-6266 (1983).

7. $\quad$ Y. M. Gupta, J. Appl. Phys. 54, 6094-6098 (1983).

8. D. Y. Chen, Y. M. Gupta, and M. H. Miles, J. Appl. Phys. 55, 3984-3993 (1984).

9. $\quad$ S. C. Gupta and Y. M. Gupta, J. Appl. Phys. 57, 2464-2473 (1985).

10. $\quad$ N. S. Brar and Y. M. Gupta, J. Appl. Phys. 61, 1304-1310 (1987).

11. M. K. W. Wong, Ph.D. Thesis, Washington State University, 1991.

12. R. Feng, Y. M. Gupta, and M. K. W. Wong, Journal of Applied Physics 82, 2845-2854 (1997).

13. $\quad$ R. Feng and Y. M. Gupta, J. Appl. Phys. 83, 747-753 (1998).

14. Z. Rosenberg, D. Yaziv, and Y. Partom, J. Appl. Phys. 51, 3702-3705 (1980).

15. Z. Rosenberg, Y. Partom, M. Mayseless, and J. Falcovitz, J. Appl. Phys. 56, 1434-1439 (1984).

16. Z. Rosenberg and Y. Partom, J. Appl. Phys. 58, 3072-3076 (1985).

17. Z. Rosenberg and Y. Partom, J. Appl. Phys. 57, 5084-5086 (1985).

18. Z. Rosenberg and Y. Partom, J. Appl. Phys. 58, 1814-1818 (1985).

19. Z. Rosenberg and N. S. Brar, in High Pressure Science and Technology, (AIP Conference Proceedings, Melville, NY, 1993), pp. 1707-1710. 
20. Z. Rosenberg and N. S. Brar, J. Appl. Phys. 77, 1443-1448 (1995).

21. J. C. F. Millett, N. K. Bourne, and Z. Rosenberg, J. Phys D. 29, 2466-2472 (1996).

22. P. Church, R. Townsly, and J. Millett, in Shock Compression of Condensed Matter 1999, M. D. Furnish, L. C. Chhabildas, and R. S. Hixson, Eds. (AIP Conference Proceedings, Melville, NY, 2000), pp. 1083-1086.

23. Z. Rosenberg, J. Appl. Phys. 86, 3484-3486 (1999).

24. R. Feng, Y. M. Gupta, and M. K. W. Wong, J. Appl. Phys. 86, 3487-3489 (1999).

25. N. K. Bourne and Z. Rosenberg, Proc. R. Soc. London, Ser. A 455, 1259-1266 (1999).

26. J. C. F. Millett and N. K. Bourne, J. Appl. Phys. 88, 7037-7040 (2000).

27. J. C. F. Millett and N. K. Bourne, J. Appl. Phys. 89, 2576-2579 (2001).

28. J. C. F. Millett, N. K. Bourne, G. T. Gray(III), and I. P. Jones, Acta Materialia 50, 4801-4811 (2002).

29. J. C. F. Millett, N. K. Bourne, and N. R. Barnes, J. Appl. Phys. 92, 6590-6594 (2002).

30. N. K. Bourne, G. T. Gray(III), and J. C. F. Millett, J. Phys. (Paris) IV 110, 815-820 (2003).

31. G. T. Gray(III), N. K. Bourne, and J. C. F. Millett, J. Appl. Phys. 94, 6430-6436 (2003).

32. J. C. F. Millett, N. K. Bourne, and G. T. Gray(III), J. Phys. D 37, 942-947 (2004).

33. J. C. F. Millett, N. K. Bourne, and J. Akhavan, J. Appl. Phys. 95, 4722-4727 (2004).

34. G. T. Sutherland, "Ytterbium Gauge Measurements to Obtain Stress-Time Profiles in Shocked Cast Composition B-3,” Naval Surface Warfare Center report NSWC TR 87-342 (1989).

35. J. J. Dick, A. R. Martinez, and R. S. Hixson, "Plane Impact Response of PBX 9501 and its Components Below 2 GPa,” Los Alamos National Laboratory report LA-13426-MS (1998).

36. J. J. Dick, A. R. Martinez, and R. S. Hixson, in Proceedings of The 11th International Detonation Symposium, J. M. Short and J. E. Kennedy, Eds. (Office of Naval Research, Arlington, VA, 1998), p. 317.

37. J. J. Dick, in Shock Compression of Condensed Matter - 1999, M. D. Furnish, L. C. Chhabildas, and R. S. Hixson, Eds. (AIP Conference Proceedings, Melville, NY, 2000), p. 683-686.

38. Y. M. Gupta, Washington State University, personal communication, (2000).

39. A. R. Martinez, D. E. Hooks, and J. J. Dick, in Shock Compression of Condensed Matter - 2003, M. D. Furnish, Y. M. Gupta, J. Forbes, Eds. (AIP Conference Proceedings, Melville, NY, 2004).

40. L. Soulard and F. Bauer, in Shock Compression of Condensed Matter - 1989, S. C. Schmidt, J. N. Johnson, and L. W. Davison, Eds. (Elsevier, Amsterdam, 1990), p. 817.

41. Y. M. Gupta, J. Appl. Phys. 51, 5352-5361 (1980). 
This report has been reproduced directly from the best available copy. It is available electronically on the Web (http://www.doe.gov/bridge).

Copies are available for sale to U.S. Department of Energy employees and contractors from:

Office of Scientific and Technical Information P.O. Box 62

Oak Ridge, TN 37831

(865) 576-8401

Copies are available for sale to the public from: National Technical Information Service

U.S. Department of Commerce

5285 Port Royal Road

Springfield, VA 22161

(800) 553-6847 


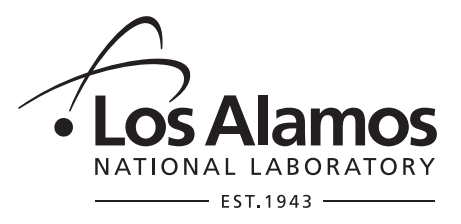

